\title{
COMPARISON OF VASOPRESSIN AND PHENYLEPHRINE IN TREATMENT OF DOPAMINE RESISTANT SEPTIC SHOCK - A RANDOMISED CONTROL TRIAL
}

\author{
MADHUSMITA PATRO, NUPUR MODA*, SUSHREE DAS, PRERNA BISWAL
}

Department of Anesthesiology and Pain Medicine, Institute of Medical Sciences and SUM Hospital, Bhubaneswar, Odisha, India. Email: drnups@yahoo.com

Received: 11 October 2020, Revised and Accepted: 19 November 2020

\section{ABSTRACT}

Objectives: Septic shock is associated with refractory hypotension and organ dysfunction and remains an important cause of mortality in intensive care units (ICUs). Vasopressors are the first-line treatment. The present study aims to compare vasopressin and phenylephrine in the management of dopamine-resistant septic shock in the ICU setting.

Methods: The study is a prospective, open-labeled, and randomized study comparing the effects of vasopressin (Group I) and phenylephrine (Group II) in the management of dopamine resistant septic shock in intensive care set up. The parameters recorded from 0 to $6 \mathrm{~h}$ after persistent hypotension despite maximum dose of dopamine were: Heart rate (HR) (beats/min), systemic blood pressure (mmHg), cardiac output (L/min), cardiac index (CI) $\left(\mathrm{L} / \mathrm{min} / \mathrm{m}^{2}\right)$, stroke volume $(\mathrm{ml})$, systemic vascular resistance index (dynes $\left./ \mathrm{cm}^{5} / \mathrm{m}^{2}\right)$, oxygen delivery index (IDO) (ml $\left.\mathrm{O}_{2} / \mathrm{min} / \mathrm{m}^{2}\right)$, urine output ( $\left.\mathrm{ml}\right)$, and serum lactate $(\mathrm{mg} / \mathrm{dl})$.

Results: There was a significant difference in HR, systolic blood pressure, cardiac output, and CI in both groups from 1 h to 6 h. The IDO had a significant rise in Group II. The serum lactate level also decreased in Group II at $6 \mathrm{~h}$.

Conclusion: From our study, we concluded that as organ perfusion and oxygenation are more important for the treatment of septic shock and to keep the vital organs functioning rather than to increase the systemic vascular resistance and blood pressure, phenylephrine showed a better result than vasopressin in the treatment of septic shock.

Keywords: Septic shock, Vasopressin, Phenylephrine, Cardiac output, Oxygen delivery index.

(C) 2021 The Authors. Published by Innovare Academic Sciences Pvt Ltd. This is an open access article under the CC BY license (http://creativecommons.org/ licenses/by/4.0/) DOI: http://dx.doi.org/10.22159/ajpcr.2021v14i1.39977. Journal homepage: https://innovareacademics.in/journals/index.php/ajpcr

\section{INTRODUCTION}

Septic shock, the most severe form of sepsis associated with refractory hypotension and organ dysfunction, is a deadly disease, which remains one of the most important causes of mortality in intensive care units (ICUs). Most deaths are associated with hypotension and multiple organ dysfunction refractory to antibiotic therapy, volume resuscitation, and inotropic support [1].

Recently, attention has been focused on optimizing oxygen transport variables, specifically oxygen delivery and consumption, in the management of sepsis [2]. However, very few data exist regarding the effects of specific vasopressors on oxygen transport indicators and serum lactate. Jain and Singh compared two vasoconstrictors norepinephrine and phenylephrine in the management of dopamineresistant septic shock and no difference was observed in any of the investigated parameters except for the statistically significant reduction of heart rate (HR) and increase in stroke volume index in the phenylephrine group as compared to the non-significant change in norepinephrine group [3]. Morelli et al. investigated the effects of firstline therapy with either phenylephrine or norepinephrine on systemic and regional hemodynamics in patients with septic shock. They suggest that there were no differences in terms of cardiopulmonary performance, global oxygen transport, and regional hemodynamics when phenylephrine was administered instead of norepinephrine in the initial hemodynamic support of septic shock [4].

PubMed was searched for relevant articles using Mesh term (["Vasopressins"(Mesh)] OR "Phenylephrine"(Mesh)] AND "Shock, Septic" (Mesh). 67 articles were found. On using filters for Clinical trial, Meta-Analysis, Randomized Controlled Trial, and Systematic Reviews,
21 articles remained. Among them, seven articles were relevant to the present study and were extensively reviewed. Liu et al. state no difference in mortality between terlipressin and norepinephrine infusion in patients with septic shock. Moreover, patients in the terlipressin group had a higher number of serious adverse events [5]. Hammond et al. suggest that overcoming vasopressin deficiency sooner may reduce the time patients spend in the early phase of septic shock [6]. Russell et al. state that selepressin $2.5 \mathrm{ng} / \mathrm{kg} / \mathrm{min}$ was able to replace norepinephrine while maintaining adequate MAP rapidly, and it may improve fluid balance and shorten the time of mechanical ventilation [7]. However, very few studies have been done to compare the effects of phenylephrine and vasopressin in the management of dopamine-resistant septic shock. The present study aims to compare vasopressin and phenylephrine in the management of dopamine-resistant septic shock in the ICU setting.

\section{METHODS}

The study is a prospective, open-labeled, and randomized study comparing the effects of vasopressin and phenylephrine in the management of dopamine-resistant septic shock in intensive care set up of IMS and SUM Hospital. The study consisted of two groups, Group I receiving vasopressin and Group II receiving phenylephrine, as shown in Fig. 1. The dose at which the drug was initiated is as follows - vasopressin at $0.01 \mathrm{units} / \mathrm{mins}$ and phenylephrine at $0.5 \mu \mathrm{g} / \mathrm{kg} / \mathrm{min}$. Dose increments were done by 0.005 units $/ \mathrm{min}$ for vasopressin and $0.5 \mu \mathrm{g} / \mathrm{kg} / \mathrm{min}$ for phenylephrine at 30 mins interval during the study on not achieving the goals. The dose range for vasopressin was $0.01-0.04$ units $/ \mathrm{min}$, and the dose range for phenylephrine is $0.5-8 \mu \mathrm{g} / \mathrm{kg} / \mathrm{min}$. Inclusion criteria for the study were: Persistent hypotension, evidence of one or more endorgan damage or infection with 2 /more of the following: Temperature $>38^{\circ} \mathrm{C}$ or $<36^{\circ} \mathrm{C}, \mathrm{HR}>90 / \mathrm{min}$, respiratory rate $>20 / \mathrm{min}$ or white blood 


\section{CONSORT DIAGRAM}

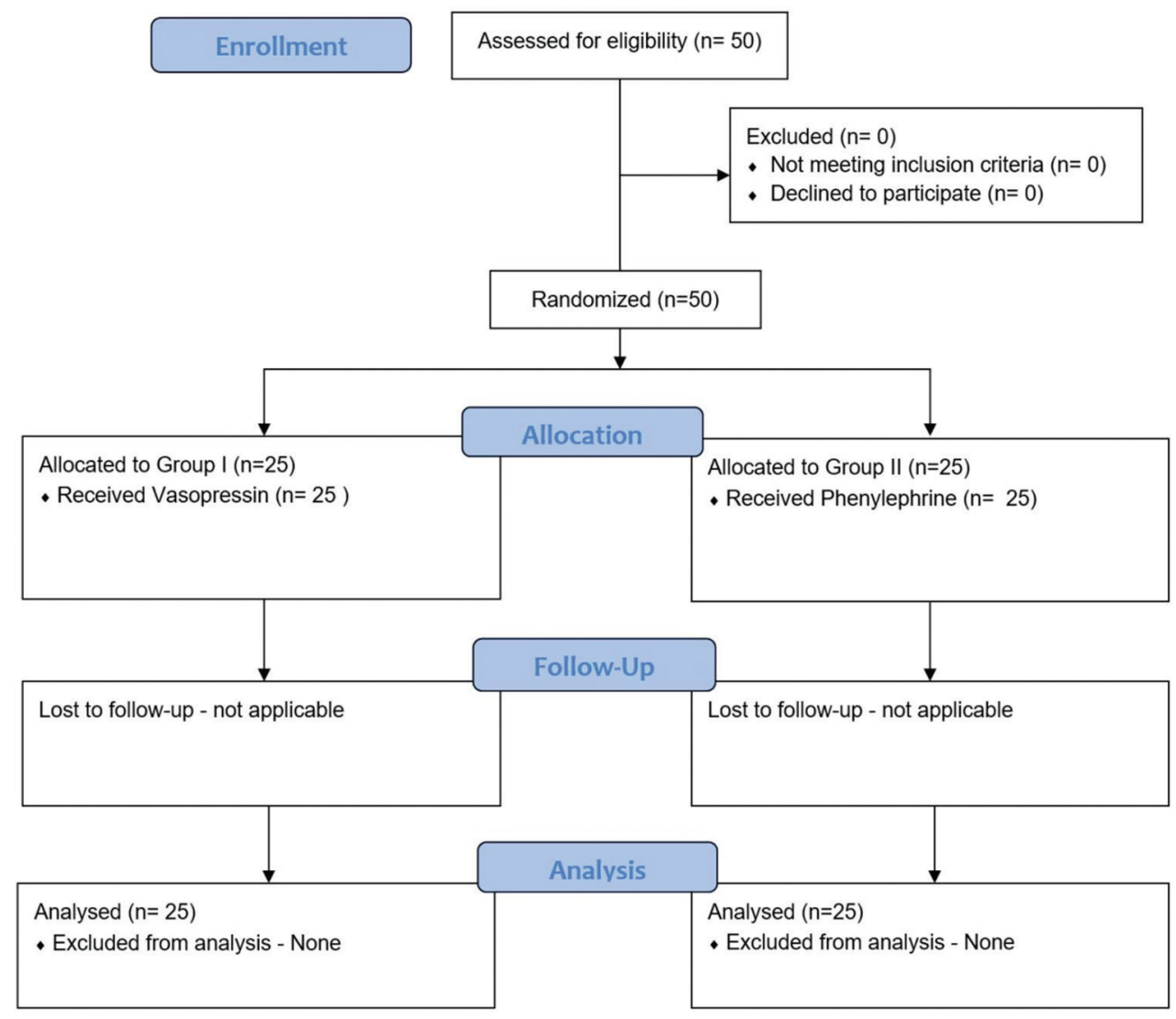

Fig. 1: Consort flow diagram for randomisation

cell count $>12,000 / \mathrm{m}^{3}$ or $<4000 / \mathrm{min}^{3}$ or $>10 \%$ band forms. Persistent hypotension was defined as systolic blood pressure $<90 \mathrm{mmHg}$ or, mean arterial pressure $<60 \mathrm{mmHg}$ with central venous pressure $>12 \mathrm{mmHg}$ or, pulmonary artery occlusion pressure $>18 \mathrm{mmHg}$, despite adequate fluid resuscitation and continuous infusion of pharmacological doses of dopamine $(25 \mu \mathrm{g} / \mathrm{kg} / \mathrm{min})$ for $1 \mathrm{~h}$. Exclusion criteria for the study were acute coronary artery disease or underlying cardiac problems, acute mesenteric ischemia, severe liver disease, chronic renal failure, and uncorrected shock due to blood loss. The goals of the drug therapy were systemic blood pressure (SBP) $>90 \mathrm{mmHg}$, systemic vascular resistance index (SVRI) $>1100$ dynes.s $/ \mathrm{cm}^{5} / \mathrm{m}^{2}$, cardiac index $(\mathrm{CI})>2.8 \mathrm{~L} / \mathrm{min} / \mathrm{m}^{2}$, or oxygen delivery index $\left(\mathrm{IDO}_{2}\right)>550 \mathrm{ml} / \mathrm{min} / \mathrm{m}^{2}$. In this procedure, the various cardiac parameters were measured by the use of Vigileo Monitor and FloTrac Sensor (introduced by Edwards Lifesciences). Attendants of the participants to this study were explained of the procedure, and informed consent was taken. The participant was randomized by computer generated numbers and allocation was done using sealed envelopes.

An arterial cannula is first introduced into the radial artery of any of the upper limb of the patient, and the FloTrac sensor is attached to it. In the FloTrac sensor, the port for the connection of the intravenous set is connected to heparinize saline, and out of the two cables, the green one was connected to the Vigileo monitor and white to the pressure monitor. The central venous oximetry catheter was also inserted to show the levels of $\mathrm{ScvO}_{2}$. Then, the patient's demographic data were fed in the Vigileo monitor to proceed, and then the "Zeroing" of the system was done to show the cardiac parameters. Baseline parameters of the patient at " 0 " $\mathrm{h}$ were recorded, and then the vasopressor agents (vasopressin/phenylephrine) were started with their respective doses, as stated before. After this, the parameters were recorded at every 30 min interval and dose increments were done as and when required to achieve the goals of therapy. The total duration of the study was $6 \mathrm{~h}$. Urine output $(\mathrm{ml})$ and serum lactate $(\mathrm{mg} / \mathrm{dl})$ levels were recorded every three hourly. The central venous pressure was maintained at 8-15 mmHg throughout the study for all the patients in both the study groups. Dopamine infusion was continued throughout the study duration at a rate of $25 \mu \mathrm{g} / \mathrm{kg} / \mathrm{min}$. The parameters recorded during the study are: HR (beats/min), SBP ( $\mathrm{mmHg}$ ), cardiac output $(\mathrm{L} / \mathrm{min})$, CI (L/min $\left./ \mathrm{m}^{2}\right)$, stroke volume ( $\mathrm{ml}$ ), SVRI (dynes $\left./ \mathrm{cm}^{5} / \mathrm{m}^{2}\right)$, IDO $\left(\mathrm{ml} \mathrm{O}_{2}\right.$ ) $\left.\mathrm{min} / \mathrm{m}^{2}\right)$, urine output $(\mathrm{ml})$, and serum lactate $(\mathrm{mg} / \mathrm{dl})$.

All procedures were followed according to the institutional ethical standards and the Helsinki Declaration of 1975, as revised in 1983. Continuous variables were analyzed with the unpaired t-test and categorical variables were analyzed with the Chi-square test and Fisher Exact test. Statistical significance was taken as $p<0.05$ and data were analyzed using SPSS software (version 20.000) and Microsoft Excel 2016.

\section{RESULTS}

Fifty patients were included in the study with Group I $(n=25)$ receiving vasopressin and Group II $(n=25)$ receiving phenylephrine. Sample size was calculated based on previous studies with confidence level are estimated at $95 \%$, Z value of 1.96 , and margin of error estimated at \pm 12 . The mean age in Group I was $35.00 \pm 6.14$ and in Group II $-36.72 \pm 5.03$ years $(p=0.284)$. Male to Female ratio was $2.12: 1$ in Group I and 1.77:1 in Group II. The mean body surface area was $1.46 \pm 0.08$ in Group I and $1.48 \pm 0.02$ in Group II ( $p=0.157)$. The HR, systolic blood pressure, cardiac output, and CI of both the groups from $0 \mathrm{~h}$ to $6 \mathrm{~h}$ are shown in Table 1. There was a significant difference in these parameters from $1 \mathrm{~h}$ to $6 \mathrm{~h}$. Stroke volume, SVRI, IDO, and central venous oxygen saturation (SCVo2) are shown in Table 2. The serum lactate levels and urine output is shown in Table 3. At $6 \mathrm{~h}$, serum lactate is significantly less in Group II. 


\section{DISCUSSION}

The baseline and at 30 min mean HR, systolic blood pressure, and cardiac output were statistically not significant in the two groups, but at all other points of time, it was statistically significant. On comparing the HR in both groups, more fall in HR was noted in Group II compared to Group I. After $30 \mathrm{~min}$ at all points, systolic blood pressure rise was more significant with Group I. The cardiac output significantly increased in Group II but gradually decreased in Group I. The CI in the two groups was comparable at baseline, $30 \mathrm{~min}, 1.5 \mathrm{~h}$, and $2 \mathrm{~h}$, but the difference was statistically significant at all other points. The trend shows that the CI has increased in Group II and decreased in Group I patients (Table 1). The stroke volume and SVRI in both groups are comparable at baseline, but after that statistically significant increase in stroke volume was observed in Group II and SVRI was significantly increased in Group I. The IDO is comparable in both the groups at baseline and $30 \mathrm{~min}$. After that, the IDO decreased significantly in Group I and increased in Group II. The values of central venous oxygen saturation were comparable between both groups (Table 2). The serum lactate levels are comparable in both the groups at baseline and $3 \mathrm{~h}$, but at $6 \mathrm{~h}$, value decreased significantly in Group II. The urine output in both the group of patients was comparable at all point of time, with no statistically significant difference (Table 3).

As compared to patients receiving vasopressin, the decrease in HR and increase in cardiac output, CI, stroke volume, and IDO was more evident in patients receiving phenylephrine. Serum lactate was also found to decrease substantially in patients receiving phenylephrine at $6 \mathrm{~h}$. Thus, phenylephrine proved to be a better vasopressor agent in dopamine resistant septic shock when compared to vasopressin. The study depicts that organ perfusion and oxygenation are more critical for the treatment of septic shock and to keep the vital organs functioning rather than to increase the systemic vascular resistance and blood pressure.

Wu et al. evaluate the effects of dopamine (DA) and norepinephrine (NE) on hemodynamics and tissue oxygenation of patients with septic shock). The results suggested that both DA and NE had a good effect on raising blood pressure; DA was more effective than $\mathrm{NE}$ in increasing oxygen delivery (D02), but its use was confined to a certain extent due to its effect of accelerating HR. NE was better than DA in improving internal organ perfusion and tissue oxygenation. NE may be a better choice for patients of septic shock with tachycardia and/or severe tissue hypoxia [8].

Table 1: Mean HR, systolic blood pressure, cardiac output, and CI in the two groups

\begin{tabular}{|c|c|c|c|c|c|c|c|c|c|c|c|c|}
\hline \multirow{2}{*}{$\begin{array}{l}\text { Time } \\
\text { interval }\end{array}$} & \multicolumn{3}{|c|}{ Mean HR } & \multicolumn{3}{|c|}{ Mean systolic blood pressure } & \multicolumn{3}{|c|}{ Mean cardiac output } & \multicolumn{3}{|c|}{ Mean cardiac index } \\
\hline & Group I & Group II & p-value & Group I & Group II & p-value & Group I & Group II & p-value & Group I & Group II & p-value \\
\hline $0 \mathrm{~min}$ & 105.72 & 107.12 & 0.467 & 87.00 & 86.48 & 0.584 & 4.356 & 4.176 & 0.087 & 2.97 & 2.89 & 0.127 \\
\hline $1 \mathrm{~h}$ & 104.20 & 93.64 & $<0.001$ & 101.04 & 93.96 & $<0.001$ & 4.050 & 4.230 & 0.015 & 2.76 & 2.59 & $<0.001$ \\
\hline $1.5 \mathrm{~h}$ & 105.28 & 87.88 & $<0.001$ & 102.68 & 98.48 & 0.002 & 4.132 & 4.440 & 0.012 & 2.84 & 2.74 & 0.252 \\
\hline $2 \mathrm{~h}$ & 100.52 & 84.76 & $<0.001$ & 103.88 & 100.68 & 0.026 & 4.208 & 4.776 & $<0.001$ & 2.88 & 2.96 & 0.349 \\
\hline $2.5 \mathrm{~h}$ & 98.92 & 82.28 & $<0.001$ & 109.16 & 100.08 & $<0.001$ & 3.944 & 4.800 & $<0.001$ & 2.68 & 2.93 & $<0.001$ \\
\hline $3 \mathrm{~h}$ & 96.68 & 77.72 & $<0.001$ & 113.92 & 98.68 & $<0.001$ & 3.856 & 4.900 & $<0.001$ & 2.60 & 3.02 & $<0.001$ \\
\hline $3.5 \mathrm{~h}$ & 96.32 & 74.88 & $<0.001$ & 117.52 & 101.20 & $<0.001$ & 3.720 & 4.980 & $<0.001$ & 2.54 & 3.05 & $<0.001$ \\
\hline $4 \mathrm{~h}$ & 93.92 & 72.16 & $<0.001$ & 118.36 & 100.64 & $<0.001$ & 4.000 & 5.032 & $<0.001$ & 2.71 & 3.10 & $<0.001$ \\
\hline $4.5 \mathrm{~h}$ & 92.60 & 72.72 & $<0.001$ & 122.88 & 102.96 & $<0.001$ & 3.744 & 4.972 & $<0.001$ & 2.54 & 3.04 & $<0.001$ \\
\hline $5 \mathrm{~h}$ & 89.60 & 69.24 & $<0.001$ & 122.44 & 101.64 & $<0.001$ & 3.900 & 5.100 & $<0.001$ & 2.66 & 3.13 & $<0.001$ \\
\hline $5.5 \mathrm{~h}$ & 92.96 & 68.60 & $<0.001$ & 124.92 & 101.56 & $<0.001$ & 3.928 & 5.156 & $<0.001$ & 2.68 & 3.20 & $<0.001$ \\
\hline $6 \mathrm{~h}$ & 91.08 & 67.88 & $<0.001$ & 126.80 & 103.84 & $<0.001$ & 3.756 & 5.080 & $<0.001$ & 2.54 & 3.13 & $<0.001$ \\
\hline
\end{tabular}

HR: Heart rate, CI: Cardiac index

Table 2: Stroke volume, SVRI, IDO, and central venous oxygen saturation in the two groups

\begin{tabular}{|c|c|c|c|c|c|c|c|c|c|c|c|c|}
\hline \multirow{2}{*}{$\begin{array}{l}\text { Time } \\
\text { interval }\end{array}$} & \multicolumn{3}{|c|}{ Stroke volume } & \multicolumn{3}{|c|}{ Systemic vascular resistance index } & \multicolumn{3}{|c|}{ Oxygen delivery index } & \multicolumn{3}{|c|}{ Central venous oxygen saturation } \\
\hline & Group I & Group II & p-value & Group I & Group II & p-value & Group I & Group II & p-value & Group I & Group II & p-value \\
\hline $0 \mathrm{~min}$ & 60.84 & 59.96 & 0.515 & 1140.76 & 1125.80 & 0.526 & 424.92 & 402.52 & 0.108 & 57.00 & 56.20 & 0.416 \\
\hline $30 \mathrm{~min}$ & 65.60 & 61.56 & 0.001 & 1187.80 & 932.08 & $<0.001$ & 428.92 & 426.16 & 0.845 & 56.96 & 56.16 & 0.396 \\
\hline $1 \mathrm{~h}$ & 68.00 & 68.32 & 0.012 & 1260.00 & 990.80 & $<0.001$ & 406.88 & 451.52 & 0.010 & 57.96 & 56.12 & 0.057 \\
\hline $1.5 \mathrm{~h}$ & 63.96 & 67.12 & 0.017 & 1370.24 & 1012.20 & $<0.001$ & 414.84 & 470.24 & 0.001 & 57.40 & 56.80 & 0.487 \\
\hline $2 \mathrm{~h}$ & 64.56 & 68.88 & 0.004 & 1542.36 & 1016.40 & $<0.001$ & 399.32 & 488.56 & $<0.001$ & 58.04 & 56.88 & 0.212 \\
\hline $2.5 \mathrm{~h}$ & 64.20 & 70.32 & $<0.001$ & 1575.20 & 1071.72 & $<0.001$ & 388.40 & 503.00 & $<0.001$ & 58.00 & 57.80 & 0.805 \\
\hline $3 \mathrm{~h}$ & 62.28 & 71.76 & $<0.001$ & 1718.76 & 1091.48 & $<0.001$ & 369.56 & 513.92 & $<0.001$ & 58.56 & 58.60 & 0.957 \\
\hline $3.5 \mathrm{~h}$ & 63.08 & 73.28 & $<0.001$ & 1767.72 & 1117.80 & $<0.001$ & 361.96 & 523.68 & $<0.001$ & 59.16 & 58.80 & 0.638 \\
\hline $4 \mathrm{~h}$ & 59.60 & 74.68 & $<0.001$ & 1883.76 & 1131.08 & $<0.001$ & 347.56 & 534.28 & $<0.001$ & 58.96 & 58.80 & 0.843 \\
\hline $4.5 \mathrm{~h}$ & 60.88 & 75.04 & $<0.001$ & 1948.88 & 1166.68 & $<0.001$ & 337.28 & 547.32 & $<0.001$ & 59.68 & 59.32 & 0.822 \\
\hline $5 \mathrm{~h}$ & 60.28 & 72.76 & $<0.001$ & 2081.24 & 1152.08 & $<0.001$ & 329.64 & 552.28 & $<0.001$ & 59.24 & 58.36 & 0.241 \\
\hline $5.5 \mathrm{~h}$ & 61.04 & 73.84 & $<0.001$ & 2095.92 & 1169.16 & $<0.001$ & 324.72 & 556.84 & $<0.001$ & 58.56 & 57.96 & 0.308 \\
\hline $6 \mathrm{~h}$ & 61.00 & 73.64 & $<0.001$ & 2117.24 & 1216.40 & $<0.001$ & 312.88 & 559.56 & $<0.001$ & 59.24 & 58.96 & 0.677 \\
\hline
\end{tabular}

SVRI: Systemic vascular resistance index, IDO: Oxygen delivery index

Table 3: Serum lactate and urine output in the two groups

\begin{tabular}{lllllll}
\hline \multirow{2}{*}{ Time interval } & \multicolumn{2}{l}{ Serum lactate } & & & \multicolumn{2}{l}{ Urine output } \\
\cline { 2 - 3 } & Group I & Group II & p-value & & Group I & Group II \\
\hline 0 & 32.12 & 31.92 & 0.920 & & 83.00 & 81.00 \\
3 & 31.56 & 29.20 & 0.248 & & 78.00 & 81.00 \\
6 & 32.04 & 27.36 & 0.017 & & 96.00 & 94.00 \\
\hline
\end{tabular}


Póvoa et al. assessed the impact of the choice of vasopressor support on mortality in patients with community-acquired septic shock. They concluded that in patients with community-acquired septic shock, norepinephrine administration could be associated with worse outcomes [9].

De Backer et al. conducted a multicenter, randomized trial, and they assigned patients with shock to receive either dopamine or norepinephrine as first-line vasopressor therapy to restore and maintain blood pressure. They concluded that there was no statistically significant difference in the rate of death between patients with shock who were treated with dopamine as the first-line vasopressor agent and those who received norepinephrine, the use of dopamine was associated with a higher number of adverse events [10].

Thus, in the present study, phenylephrine showed an increase in HR, systolic blood pressure, though it was less in comparison with vasopressin, the more significant parameters like IDO increased significantly with phenylephrine. Moreover, serum lactate also decreased with phenylephrine.

\section{CONCLUSION}

From our study, we concluded that as organ perfusion and oxygenation are more important for the treatment of septic shock and to keep the vital organs functioning rather than to increase the systemic vascular resistance and blood pressure, phenylephrine showed a better result than vasopressin in the treatment of septic shock.

\section{AUTHORS' CONTRIBUTIONS}

Madhusmita Patro - acquisition of data, writing manuscript, interpretation of data, final approval. Nupur Moda - concept and designing, interpretation of data, writing the manuscript, data collection, final approval. Sushree Das - data collection, final approval. Prerna Biswal - data collection, final approval.

\section{CONFLICTS OF INTEREST}

The authors declare that there are no conflicts of interest.

\section{AUTHORS' FUNDING}

None.

\section{REFERENCES}

1. Hotchkiss RS, Moldawer LL, Opal SM, Reinhart K, Turnbull IR, Vincent JL. Sepsis and septic shock. Nat Rev Dis Primers 2016;2:16045

2. Barzegar E, Ahmadi A, Mousavi S, Nouri M, Mojtahedzadeh M. The therapeutic role of vasopressin on improving lactate clearance during and after vasogenic shock: Microcirculation, is it the black box? Acta Med Iran 2016;54:15-23

3. Jain G, Singh DK. Comparison of phenylephrine and norepinephrine in the management of dopamine-resistant septic shock. Indian J Crit Care Med 2010;14:29-34.

4. Morelli A, Lange M, Ertmer C, Dünser M, Rehberg S, Bachetoni A, et al. Short-term effects of phenylephrine on systemic and regional hemodynamics in patients with septic shock: A crossover pilot study. Shock 2008;29:446-51.

5. Liu ZM, Chen J, Kou Q, Lin Q, Huang X, Tang Z, et al. Terlipressin versus norepinephrine as infusion in patients with septic shock: A multicentre, randomised, double-blinded trial. Intensive Care Med 2018;44:1816-25.

6. Hammond DA, Ficek OA, Painter JT, McCain K, Cullen J, Brotherton AL, et al. Prospective open-label trial of early concomitant vasopressin and norepinephrine therapy versus initial norepinephrine monotherapy in septic shock. Pharmacotherapy 2018;38:531-8.

7. Russell JA, Vincent JL, Kjølbye AL, Olsson H, Blemings A, Spapen H, et al. Selepressin, a novel selective vasopressin $\mathrm{V}_{1 \mathrm{~A}}$ agonist, is an effective substitute for norepinephrine in a phase IIa randomized, placebo-controlled trial in septic shock patients. Crit Care 2017;21:213.

8. Wu LJ, He QY, Li G, Liu X. Effects of acute hypervolemic hemodilution with hydroxyethyl starch 130/0.4 on the lung in a rabbit model of sepsis. Zhongguo Wei Zhong Bing Ji Jiu Yi Xue 2008;20:18-22.

9. Póvoa PR, Carneiro AH, Ribeiro OS, Pereira AC; Portuguese Community-Acquired Sepsis Study Group. Influence of vasopressor agent in septic shock mortality. Results from the Portuguese Community-Acquired Sepsis Study (SACiUCI study). Crit Care Med 2009:37:410-6.

10. De Backer D, Biston P, Devriendt J, Madl C, Chochrad D, Aldecoa C, et al. Comparison of dopamine and norepinephrine in the treatment of shock. N Engl J Med 2010;362:779-89. 